\title{
COPD phenotypes: differences in survival
}

This article was published in the following Dove Press journal: International Journal of COPD

\section{Julio Hernández Vázquez' Ismael Ali García' Rodrigo Jiménez-García ${ }^{2}$ Alejandro Álvaro $\mathrm{Meca}^{2}$ Ana López de Andrés ${ }^{2}$ Carmen Matesanz Ruiz' María Jesús Buendía García' Javier de Miguel Díez}

'Respiratory Department, Hospital Universitario Infanta Leonor, Madrid, Spain; ${ }^{2}$ Preventive Medicine and Public Health Teaching and Research Unit, Health Sciences Faculty, Rey Juan Carlos University, Alcorcón, Madrid, Spain; ${ }^{3}$ Respiratory Department, Hospital General Universitario Gregorio Marañón, Facultad de Medicina, Universidad Complutense de Madrid (UCM), Instituto de Investigación Sanitaria Gregorio Marañón (IISGM), Madrid, Spain
Correspondence: Rodrigo Jiménez-García Preventive Medicine and Public Health Teaching and Research Unit, Health Sciences Faculty, Rey Juan Carlos University, Avda Atenas sn., Alcorcón, 28922 Madrid, Spain

Tel +34 9l 4888853

Email rodrigo.jimenez@urjc.es
Background: The aim of the study was to analyze the characteristics and survival of a group of patients with COPD according to their clinical phenotype.

Patients and methods: The study population was selected from patients undergoing scheduled spirometry between January 1, 2011 and June 30, 2011 at the respiratory function laboratory of a teaching hospital and comprised those with a previous and confirmed diagnosis of COPD and forced expiratory volume in the first second $\left(\mathrm{FEV}_{1}\right)$ of $<70 \%$. The patients selected were classified into 4 groups: positive bronchodilator response, non-exacerbator, exacerbator with emphysema, and exacerbator with chronic bronchitis. Patients were followed up until April 2017.

Results: We recruited 273 patients, of whom $89 \%$ were men. The distribution by phenotype was as follows: non-exacerbator, $47.2 \%$; positive bronchodilator response, $25.8 \%$; exacerbator with chronic bronchitis, $13.8 \%$; and exacerbator with emphysema, $13.0 \%$. A total of 90 patients died during follow-up (32.9\%). Taking patients with a positive bronchodilator response as the reference category, the risk factors that were independently associated with death were older age

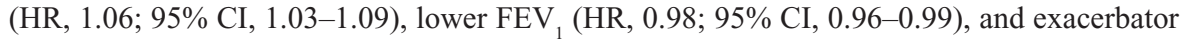
with chronic bronchitis phenotype (HR, 3.28; 95\% CI, 1.53-7.03).

Conclusion: Classification of COPD patients by phenotype makes it possible to identify subgroups with different prognoses. Thus, mortality was greater in exacerbators with chronic bronchitis and lower in those with a positive bronchodilator response.

Keywords: COPD, phenotypes, positive bronchodilator response, chronic bronchitis, emphysema, exacerbator, mortality

\section{Introduction}

COPD is a common, preventable, and treatable condition that is characterized by persistent limitation of airflow as a consequence of exposure to harmful gases or particles. $^{1}$

In clinical practice, we can see that the clinical presentation, response to therapy, and progression of COPD differ between patients. Consequently, it is increasingly clear that to evaluate the complexity of the disease, we cannot base our approach exclusively on the degree of airflow obstruction. In this sense, symptoms and exacerbations are particularly important and can help to identify different clinical forms of the disease. A phenotype of COPD is considered a set of attributes that, either alone or in combination, enable us to describe the differences between COPD patients based on clinically significant parameters (symptoms, exacerbations, response to treatment, rate of disease progression, and mortality). ${ }^{2}$

Spanish COPD guidelines (GesEPOC) ${ }^{3}$ classify patients according to their predominant pattern, emphysema, or chronic bronchitis, together with the frequency of exacerbations. Thus, GesEPOC also describes the mixed phenotype asthma-COPD overlap (ACO). 
Several studies have analyzed the prognosis for each of the phenotypes. The chronic bronchitis phenotype is clearly associated with exacerbations, admissions to hospital due to exacerbation, and mortality. ${ }^{4-8}$ The case of ACO is more controversial. While some authors report a higher incidence of exacerbation ${ }^{9,10}$ and mortality in this phenotype, ${ }^{11,12}$ others have not detected a higher incidence of exacerbations. ${ }^{13} \mathrm{Com}-$ pared with the other phenotypes of COPD, ACO has even been reported to have a "protective effect" against mortality. ${ }^{3-15}$

The objective of the present study was to analyze the characteristics and survival of a group of patients with COPD according to their clinical phenotype.

\section{Patients and methods}

This study was approved by the Gregorio Marañon Hospital Ethics Committee. Patients provided written informed consent to participate in the study. The study population was selected from all patients who underwent scheduled spirometry between January 1, 2001 and June 30, 2011 at the respiratory function laboratory of a teaching hospital and included those with a previous and subsequently confirmed diagnosis of COPD by spirometry (by confirming the existence of a forced expiratory volume in the first second $\left[\mathrm{FEV}_{1}\right] /$ forced vital capacity ratio $<0.70$ after the bronchodilator test) and $\mathrm{FEV}_{1}$ of $<70 \%$.

The patients selected were classified into 4 groups: positive bronchodilator response, non-exacerbator, exacerbator with emphysema, and exacerbator with chronic bronchitis. First, all patients with an increase in $\mathrm{FEV}_{1}>12 \%$ and $>200 \mathrm{~mL}$ in the bronchodilator test result were included in the positive bronchodilator response group. Next, all patients who had visited the emergency department less than twice for a respiratory complaint but did not require admission for the complaint during the year before the initial spirometry test were included in the non-exacerbator group. Patients who had been admitted for a respiratory complaint during the year before undergoing spirometry were included in the exacerbator with emphysema group or exacerbator with chronic bronchitis group according to the information in the clinical history and the following criteria. Patients were identified as belonging to the exacerbator with emphysema phenotype when, in addition to the criteria for exacerbation, they had radiological and/or functional abnormalities (diffusion capacity of carbon monoxide) compatible with pulmonary emphysema. Patients in the exacerbator with chronic bronchitis group had to present the criteria for exacerbation and have had productive cough for 3 months per year for at least 2 consecutive years.
The variables recorded at inclusion were age, sex, body mass index (BMI), smoking history, comorbidities (arterial hypertension, diabetes mellitus, dyslipidemia, ischemic heart disease, atrial fibrillation, cerebrovascular accident), blood eosinophil count, lung function parameters, and treatment of respiratory disease.

Follow-up was until April 1, 2017. Patients' death was recorded on this date; if the patient had not died, the last date the patient was known to be alive was recorded. During follow-up, dates of and reasons for visits to the emergency department and admissions to hospital, specifically for exacerbations of COPD and pneumonia, were recorded. Dates and causes of death were obtained from the clinical history.

\section{Statistical analysis}

The results for continuous variables are presented as mean and $\mathrm{CI}$; the results for categorical variables are presented as frequency and percentage.

Categorical data and proportions were analyzed using the $\chi^{2}$ or Fisher exact test, as applicable. Continuous variables were compared using an analysis of variance or the Kruskal-Wallis test.

Survival was analyzed taking the date of inclusion in the study as the reference point. The study ran from the day the initial spirometry test was performed until death or the last date the patient was known to be alive. A Kaplan-Meier analysis was performed to estimate the cumulative probability of death according to phenotype. The log-rank test was used for univariate comparisons between groups. Lastly, multivariate Cox regression analysis was used to test the association between phenotype and death, with an adjustment for age, sex, and $\mathrm{FEV}_{1}$.

The statistical analysis was performed using $\mathrm{R}$, version 3.4.3. Statistical significance was set at $p<0.05$.

\section{Results}

We recruited 273 patients, of whom $89 \%$ were men (Table 1). Mean age was 67.99 years $(95 \%$ CI, 66.72-69.25). Mean BMI was $28.05 \mathrm{~kg} / \mathrm{m}^{2}$ (95\% CI, 27.40-28.71). Most patients were smokers (33.7\%) and ex-smokers (64.5\%); $1.1 \%$ of the patients were nonsmokers. The most common comorbidities were arterial hypertension (53.5\%), dyslipidemia (39.6\%), diabetes mellitus (26\%), ischemic heart disease (13.9\%), atrial fibrillation (12.8\%), and cerebrovascular accidents (8.1\%). The mean eosinophil percentage was $2.42 \%$ (95\% CI, $2.22 \%-$ $2.63 \%$ ), and the mean $\mathrm{FEV}_{1}$ was $48.64 \%$ (95\% CI, $47.14 \%-$ $50.14 \%$ ). As for treatment, $93 \%$ of patients were receiving anticholinergic drugs, $88.6 \%$ long-acting $\beta_{2}$-adrenergic agonists, and $77.7 \%$ inhaled corticosteroids. 
Table I General characteristics of the study patients

\begin{tabular}{|c|c|}
\hline Parameter & Value \\
\hline Patients, $\mathrm{n}$ & 273 \\
\hline Age, years & $67.99(66.72-69.25)$ \\
\hline Men, n (\%) & $243(89)$ \\
\hline BMI, kg/m² & $28.05(27.40-28.7 I)$ \\
\hline \multicolumn{2}{|l|}{ Smoking status, n (\%) } \\
\hline Nonsmoker & $3(1.1)$ \\
\hline Smoker & $92(33.7)$ \\
\hline Ex-smoker & $176(64.5)$ \\
\hline Unknown & $2(0.7)$ \\
\hline Diabetes mellitus, n (\%) & $71(26)$ \\
\hline Arterial hypertension, n (\%) & 146 (53.5) \\
\hline Dyslipidemia, n (\%) & 108 (39.6) \\
\hline Ischemic heart disease, n (\%) & 38 (I3.9) \\
\hline Atrial fibrillation, n (\%) & $35(12.8)$ \\
\hline Cerebrovascular accident, n (\%) & $22(8.1)$ \\
\hline Eosinophils, absolute value & 202.93 (185.18-220.68) \\
\hline Eosinophils, \% & $2.42(2.22-2.63)$ \\
\hline $\mathrm{FEV}_{1}, \mathrm{~mL}$ & I,22I.39 (I,I7I.76-I,27I.02) \\
\hline $\mathrm{FEV}_{1}, \%$ & $48.64(47.14-50.14)$ \\
\hline \multicolumn{2}{|l|}{ Treatment, n (\%) } \\
\hline LAMA & $254(93)$ \\
\hline LABA & $242(88.6)$ \\
\hline Inhaled corticosteroid & $212(77.7)$ \\
\hline Roflumilast & $7(2.6)$ \\
\hline Theophylline & $15(5.5)$ \\
\hline $\mathrm{COH}$ & $91(33.5)$ \\
\hline CPAP & $31(11.4)$ \\
\hline BiPAP & $14(5.1)$ \\
\hline Mortality, n (\%) & $90(32.9)$ \\
\hline
\end{tabular}

Abbreviations: $\mathrm{BMI}$, body mass index; $\mathrm{FEV}_{\text {, }}$, forced expiratory volume in the first second; LABA, long-acting $\beta_{2}$-adrenergic agonists; CPAP, continuous positive airway pressure; BiPAP, bilevel positive airway pressure; $\mathrm{COH}$, continuous home oxygen therapy.

In relation to the distribution of phenotypes, non-exacerbators accounted for $47.2 \%$ of patients, $25.8 \%$ of patients had a positive bronchodilator response, $13.8 \%$ were exacerbators with chronic bronchitis, $13.0 \%$ were exacerbators with emphysema, with mean values of diffusion capacity of carbon monoxide (DLCO) and $\mathrm{KCO}$ (DLCO/alveolar volume) of 57.54 (95\% CI 45.41-69.67) and 61.20 (95\% CI 48.72-73.68), respectively, in this last group. Table 2 shows the characteristics of patients according to phenotype. We found significant differences in age (lower in patients with a positive bronchodilator response), smoking (more active smokers in patients with a positive bronchodilator response), some comorbid conditions (lower percentage of patients with hypertension and ischemic heart disease among patients with a positive bronchodilator response), the eosinophil count and percentage (higher in patients with a positive bronchodilator response), and $\mathrm{FEV}_{1}$ (higher in patients with a positive bronchodilator response). Significant differences were also found for mortality, which was lower in patients with a positive bronchodilator response.
Ninety patients (32.9\%) died during follow-up. Table 3 shows the causes of death according to phenotype. The most frequent cause was respiratory disease (acute exacerbation of COPD/pneumonia/sepsis), irrespective of the phenotype analyzed, followed by cancer.

Survival is shown according to phenotype in Figure 1. The factors that were independently associated with survival age, $\mathrm{FEV}_{1}$, and the exacerbator with chronic bronchitis phenotype - are shown in Table 4 . The risk of mortality increased with age (HR, 1.06; 95\% CI, 1.03-1.09), and increased with the decrease in $\mathrm{FEV}_{1}(\mathrm{HR}, 0.98 ; 95 \% \mathrm{CI}$, 0.96-0.99). The risk of mortality was significantly greater in exacerbators with chronic bronchitis than in patients with a positive bronchodilator response (HR, 3.28; 95\% CI, 1.53-7.03).

\section{Discussion}

The main conclusion of our study is that the classification by phenotype among patients with COPD makes it possible to identify subgroups with different prognoses. Thus, survival was greater in patients with a positive bronchodilator response and lower in exacerbators with chronic bronchitis.

Previous studies have shown that $6 \%-25 \%$ of patients with COPD have ACO. ${ }^{14-21}$ In our study, $25.8 \%$ of patients had a positive bronchodilator response. This figure fell within the range of reversibility detected by other authors in a similar percentage of patients $(21 \%-27.6 \%){ }^{13,22}$ Furthermore, the $\mathrm{FEV}_{1}$ of patients with a positive bronchodilator response in our study was higher than that of the other phenotypes. Similar results were reported by Calle Rubio et al, ${ }^{18}$ although this finding was not reported elsewhere. ${ }^{10,14}$

Non-exacerbators accounted for $47.2 \%$ of patients, exacerbators with chronic bronchitis accounted for $13.8 \%$, and exacerbators with emphysema accounted for $13.0 \%$. This distribution is similar to that reported in other studies, which show non-exacerbator to be the most frequent phenotype. ${ }^{18-21}$ However, a recent study performed in primary care in Russia showed that the most common phenotype was exacerbator with chronic bronchitis, with only $36 \%$ of patients classified as non-exacerbators. The authors also indicated that these results were associated with the difficulty in diagnosing COPD in Russia. ${ }^{23}$ Consistent with previous studies, patients with chronic bronchitis were frequent among exacerbators. ${ }^{20,21}$

Severe exacerbations seem to be an independent risk factor for death, ${ }^{24-26}$ with the result that the frequency of exacerbations increases the risk of death. The risk of death increases 2 -fold in patients with 1 or 2 severe exacerbations 
Table 2 Characteristics of the study population by phenotype

\begin{tabular}{|c|c|c|c|c|c|}
\hline Variable & $\begin{array}{l}\text { Positive bronchodilator } \\
\text { response }\end{array}$ & $\begin{array}{l}\text { Non- } \\
\text { exacerbator }\end{array}$ & $\begin{array}{l}\text { Exacerbator } \\
\text { with emphysema }\end{array}$ & $\begin{array}{l}\text { Exacerbator } \\
\text { with chronic } \\
\text { bronchitis }\end{array}$ & $p$-value \\
\hline Patients, $\mathrm{n}$ & 71 & 130 & 36 & 38 & \\
\hline Age, years & $63.44(60.83-66.04)$ & $\begin{array}{l}69.67(68.07- \\
71.27)\end{array}$ & $\begin{array}{l}68.44(64.88- \\
72.01)\end{array}$ & $\begin{array}{l}71.16(68.15- \\
74.16)\end{array}$ & 0.001 \\
\hline Men, n (\%) & $63(88.7)$ & $119(91.5)$ & $31(86.1)$ & $32(84.2)$ & 0.558 \\
\hline $\mathrm{BMI}, \mathrm{kg} / \mathrm{m}^{2}$ & $28.15(26.94-29.36)$ & $\begin{array}{l}28.6 I(27.6 I- \\
29.6 I)\end{array}$ & $\begin{array}{l}26.69(25.06- \\
28.32)\end{array}$ & $\begin{array}{l}27.01(25.94- \\
28.08)\end{array}$ & 0.121 \\
\hline \multicolumn{6}{|l|}{ Smoking status, n (\%) } \\
\hline Nonsmoker & $0(0)$ & $3(2.3)$ & $0(0)$ & $0(0)$ & 0.336 \\
\hline Smoker & $35(49.3)$ & $35(27.1)$ & II (30.6) & $13(35.1)$ & 0.017 \\
\hline Ex-smoker & $36(50.7)$ & 91 (70.5) & $25(69.4)$ & $24(64.9)$ & 0.039 \\
\hline Unknown & $0(0)$ & I (0.8) & $0(0)$ & I (2.6) & $0.44 I$ \\
\hline Diabetes mellitus, n (\%) & $16(22.5)$ & $32(24.6)$ & $13(36.1)$ & II (28.9) & 0.45 \\
\hline Arterial hypertension, n (\%) & $28(39.4)$ & $80(6 \mid .5)$ & $18(50)$ & $22(57.9)$ & 0.023 \\
\hline Dyslipidemia, n (\%) & $24(33.8)$ & $56(43.1)$ & $10(27.8)$ & $12(31.6)$ & 0.245 \\
\hline Ischemic heart disease, n (\%) & $4(5.6)$ & $18(13.8)$ & $4(I I . I)$ & $14(36.8)$ & $<0.001$ \\
\hline Atrial fibrillation, $\mathrm{n}(\%)$ & $4(5.6)$ & $18(13.8)$ & $5(13.9)$ & $9(23.7)$ & 0.063 \\
\hline Cerebrovascular accident, n (\%) & $3(4.2)$ & $14(10.8)$ & $3(8.3)$ & $2(5.3)$ & 0.373 \\
\hline Eosinophils, absolute value & $235.2 I(200.1 I-270.32)$ & $\begin{array}{l}215.38(190.99- \\
239.78)\end{array}$ & $\begin{array}{l}150(111.16- \\
188.84)\end{array}$ & $\begin{array}{l}\text { II } 8.42(82.48- \\
154.36)\end{array}$ & $<0.001$ \\
\hline Eosinophils, \% & $2.73(2.34-3.12)$ & $2.6(2.31-2.9)$ & $1.76(1.33-2.18)$ & $1.58(1.15-2.02)$ & $<0.001$ \\
\hline $\mathrm{FEV}_{1}, \%$ & $53.7 \mid(5|| 2-56.3 \mid)$. & $48.69(46.57-50.8)$ & $42.31(38.92-45.7)$ & $42.87(39.32-46.42)$ & $<0.001$ \\
\hline $\mathrm{FEV}_{1}, \mathrm{~mL}$ & I,450.7 (I,358.4-I,543.0I) & $\begin{array}{l}\mathrm{I}, 197.62(\mathrm{I}, \mid 3 \mathrm{I} .72- \\
\mathrm{I}, 263.5 \mathrm{I})\end{array}$ & $\begin{array}{l}995.56(9 \mid 2.42- \\
1,078.69)\end{array}$ & $\begin{array}{l}985.79(889.16- \\
1,082.42)\end{array}$ & $<0.001$ \\
\hline Mortality, n (\%) & $12(16.9)$ & $44(33.8)$ & $15(41.7)$ & $19(50)$ & 0.002 \\
\hline \multicolumn{6}{|l|}{ Treatment, n (\%) } \\
\hline Anticholinergic drugs & $60(84.5)$ & $124(95.4)$ & $35(97.2)$ & $38(100)$ & 0.004 \\
\hline LABA & $66(93)$ & $107(82.3)$ & $35(97.2)$ & $37(97.4)$ & 0.006 \\
\hline Inhaled corticosteroids & $61(85.9)$ & $87(66.9)$ & $33(91.7)$ & $35(92.1)$ & $<0.001$ \\
\hline Roflumilast & $2(2.8)$ & $2(1.5)$ & $2(5.6)$ & I (2.6) & 0.6 \\
\hline Theophylline & I (I.4) & $5(3.8)$ & $5(13.9)$ & $6(15.8)$ & 0.003 \\
\hline $\mathrm{COH}$ & $14(19.7)$ & $38(29.5)$ & $21(58.3)$ & $24(63.2)$ & $<0.001$ \\
\hline CPAP, BiPAP & $10(14.1)$ & $16(12.3)$ & $3(8.3)$ & $2(5.3)$ & 0.497 \\
\hline
\end{tabular}

Abbreviations: BMI, body mass index; $\mathrm{FEV}_{1}$, forced expiratory volume in the first second; LABA, long-acting $\beta_{2}$-adrenergic agonists; CPAP, continuous positive airway pressure; BiPAP, bilevel positive airway pressure; $\mathrm{COH}$, continuous home oxygen therapy.

(requiring a visit to the emergency department or admission to hospital) compared with non-exacerbators; the risk is 4-fold greater in patients with 3 or more severe exacerbations per year. ${ }^{24}$ These data have been confirmed in other studies, which show that the risk of death is even independent of the BODE index. ${ }^{25}$ Other authors have also shown that the risk of death increases with the number of hospitalizations, as does the risk of a subsequent admission. ${ }^{26} \mathrm{We}$ found that exacerbators with chronic bronchitis have a 3-fold greater risk of death than patients with a positive bronchodilator

Table 3 Cause of death according to phenotype

\begin{tabular}{|c|c|c|c|c|c|c|c|c|c|c|}
\hline \multirow[t]{2}{*}{ Cause } & \multicolumn{2}{|c|}{ Total } & \multicolumn{2}{|c|}{$\begin{array}{l}\text { Positive bronchodilator } \\
\text { response }\end{array}$} & \multicolumn{2}{|c|}{$\begin{array}{l}\text { Non- } \\
\text { exacerbator }\end{array}$} & \multicolumn{2}{|c|}{$\begin{array}{l}\text { Exacerbator } \\
\text { with emphysema }\end{array}$} & \multicolumn{2}{|c|}{$\begin{array}{l}\text { Exacerbator with } \\
\text { chronic bronchitis }\end{array}$} \\
\hline & $\mathbf{n}$ & $\%$ & $\mathbf{n}$ & $\%$ & $\mathbf{n}$ & $\%$ & $\mathbf{n}$ & $\%$ & $\mathbf{n}$ & $\%$ \\
\hline $\begin{array}{l}\text { Acute exacerbation of COPD/ } \\
\text { pneumonia/respiratory sepsis }\end{array}$ & 42 & 46.67 & 5 & 41.67 & 18 & 40.91 & 9 & 60 & 10 & 52.63 \\
\hline Cancer & 23 & 25.56 & 4 & 33.33 & II & 25 & 3 & 20 & 5 & 26.32 \\
\hline Heart disease & 2 & 2.22 & 0 & 0 & 2 & 4.55 & 0 & 0 & 0 & 0 \\
\hline Other & 3 & 3.33 & 0 & 0 & I & 2.27 & I & 6.67 & I & 5.26 \\
\hline Not available & 20 & 22.22 & 3 & 25 & 12 & 27.27 & 2 & 13.33 & 3 & 15.79 \\
\hline
\end{tabular}




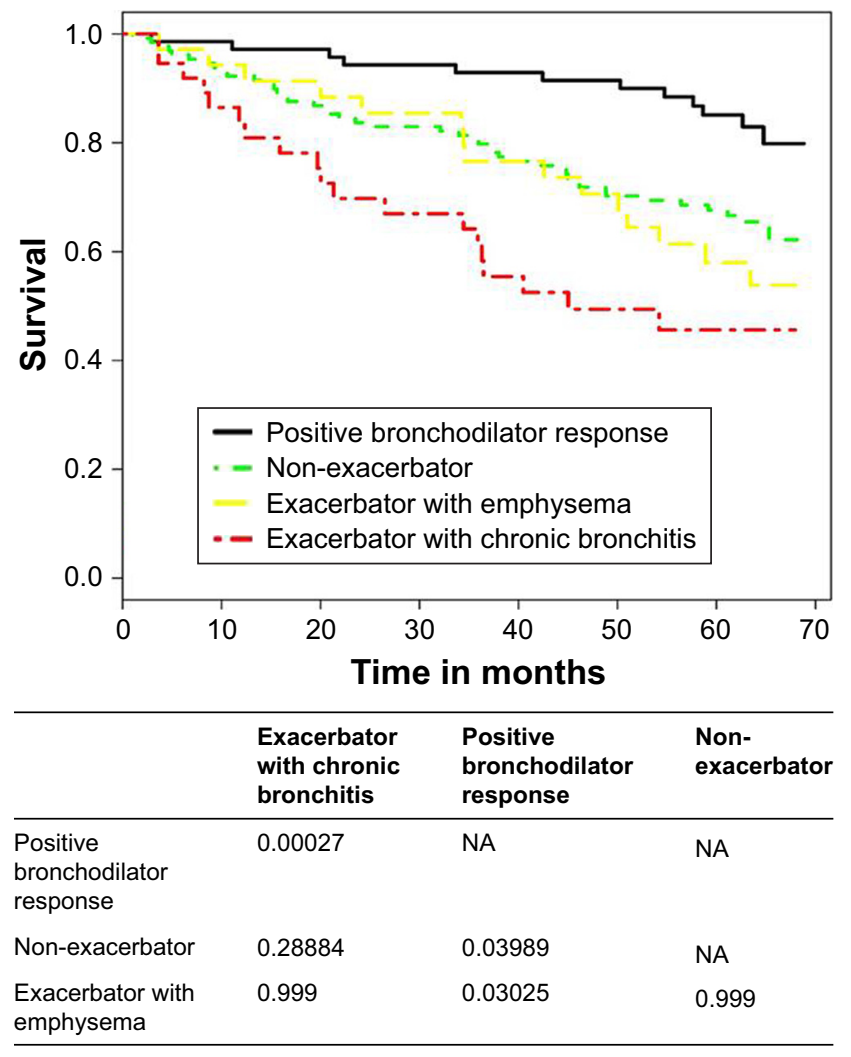

Figure I Kaplan-Meier survival curves according to the phenotype of COPD. Note: $p$-value for the comparison of survival curves using the log-rank test. Abbreviation: NA, not applicable.

response. In this way, it is important to optimize the treatment of these patients. The first step of treatment in patients with exacerbator phenotype with chronic bronchitis is the double bronchodilator therapy, and the next step is to identify the best option for each patient according to their characteristics. These options include drugs such as inhaled corticosteroids and mucolytics, as well as long-term phosphodiesterase 4 inhibitors and antibiotics. $^{27}$

Table 4 Factors independently associated with mortality (Cox regression)

\begin{tabular}{|c|c|c|c|}
\hline Variable & $\begin{array}{l}\text { Hazard } \\
\text { ratio }\end{array}$ & $95 \% \mathrm{Cl}$ & $p$-value \\
\hline Age & 1.06 & $1.03-1.09$ & $<0.001$ \\
\hline \multicolumn{4}{|l|}{ Sex } \\
\hline Female & 1 & & \\
\hline Male & 2.10 & $0.74-5.91$ & 0.158 \\
\hline $\mathrm{FEV}_{1}$ & 0.98 & $0.96-0.99$ & 0.044 \\
\hline \multicolumn{4}{|l|}{ Phenotype } \\
\hline Positive bronchodilator response & I & & \\
\hline Non-exacerbator & 1.67 & $0.87-3.20$ & 0.122 \\
\hline Exacerbator with emphysema & 2.04 & $0.91-4.56$ & 0.079 \\
\hline Exacerbator with chronic bronchitis & 3.28 & $1.53-7.03$ & 0.002 \\
\hline
\end{tabular}

Abbreviation: $\mathrm{FEV}_{\mathrm{l}}$, forced expiratory volume in I second.
Disease progression is the main cause of death in patients with COPD. ${ }^{28}$ In our setting, 50\%-80\% of COPD patients died of exacerbation ( $30 \%-50 \%)$, lung cancer $(8.5 \%-27 \%)$, or other respiratory diseases. ${ }^{29-33}$ In the early stages of COPD, the causes of death are mainly non-respiratory, although most are associated with smoking (cancer, ischemic heart disease, and cerebrovascular accident). ${ }^{28}$ In the case of patients with COPD and chronic respiratory insufficiency, Zielinski et $\mathrm{al}^{34}$ observed that the main causes of death were exacerbation of chronic respiratory insufficiency (38\%), heart failure $(13 \%)$, respiratory infection (11\%), pulmonary thromboembolism (10\%), cardiac arrhythmias (8\%), and lung cancer $(7 \%)$. In our study, the trend was similar, with respiratory disease (exacerbation of COPD, pneumonia, and respiratory sepsis) being the main cause, followed by cancer, mainly lung cancer.

Our results were obtained under real-world conditions and show that a simple positive bronchodilator response, which is therefore less demanding than the current criteria for ACO, makes it possible to identify a subgroup of patients with COPD and a more favorable course than the other phenotypes. They also show that mortality is higher in exacerbators with chronic bronchitis. The worst prognosis found in patients with exacerbator phenotype with chronic bronchitis is in line with other studies that have been previously published. For example, De Abajo Larriba et $\mathrm{al}^{35}$ have recently described that these patients are more severe, have more exacerbations, and require more income than the other phenotypes.

Our study is subject to a series of limitations. First, the study was performed in a single center, thus limiting the generalizability of the results. Second, due to the design characteristics of our study, it was not possible to collect the exacerbations diagnosed and treated ambulatory by primary care physicians; only exacerbations management in the emergency department were considered. Third, the lack of active follow-up implies that for patients who died outside the hospital, we could not register the cause of death in some cases. Lastly, some of the variables that might have influenced the results - cumulative smoking, duration of COPD, and treatment of comorbidities - were not available.

In conclusion, classification of COPD patients by phenotype makes it possible to identify subgroups with different prognoses. Mortality was higher in patients with the exacerbator with chronic bronchitis phenotype than in the positive bronchodilator response phenotype. It is clear that the treatment and the clinical progress of patients with 
COPD must be improved in exacerbators with chronic bronchitis.

\section{Acknowledgment}

The authors would like to thank Menarini for grant support.

\section{Disclosure}

The authors report no conflicts of interest in this work.

\section{References}

1. Global Initiative for Chronic Obstructive Lung Disease (GOLD) 2017. Global Strategy for the Diagnosis, Management and Prevention of COPD. 2017. Available from: http://goldcopd.org. Accessed July 7, 2018.

2. Han MK, Agusti A, Calverley PM, et al. Chronic obstructive pulmonary disease phenotypes: the future of COPD. Am J Respir Crit Care Med. 2010;182(5):598-604.

3. Miravitlles M, Soler-Cataluña JJ, Calle M, et al. Guía española de la EPOC (GesEPOC). Actualización 2014. [Spanish guideline for COPD (GesEPOC). Update 2014]. Arch Bronconeumol. 2014;50 (Suppl 1): 1-16. Spanish.

4. Vestbo J, Prescott E, Lange P; Copenhagen City Heart Study Group. Association of chronic mucus hypersecretion with $\mathrm{FEV}_{1}$ decline and chronic obstructive pulmonary disease morbidity. Am J Respir Crit Care Med. 1996;153:1530-1535.

5. Pelkonen M, Notkola IL, Nissinen A, Tukiainen H, Koskela H. Thirtyyear cumulative incidence of chronic bronchitis and COPD in relation to 30-year pulmonary function and 40-year mortality: a follow-up in middle-aged rural men. Chest. 2006;130(4):1129-1137.

6. Prescott E, Lange P, Vestbo J. Chronic mucus hypersecretion in COPD and death from pulmonary infection. Eur Respir J. 1995;8(8): $1333-1338$.

7. Kim V, Criner GJ. The chronic bronchitis phenotype in chronic obstructive pulmonary disease: features and implications. Curr Opin Pulm Med. 2015;21(2):133-141.

8. Lahousse L, Seys LJM, Joos GF, Franco OH, Stricker BH, Brusselle GG. Epidemiology and impact of chronic bronchitis in chronic obstructive pulmonary disease. Eur Respir J. 2017;50(2):1602470.

9. Hardin M, Silverman EK, Barr RG, et al; COPDGene Investigators. The clinical features of the overlap between COPD and asthma. Respir Res. 2011;12:127.

10. Bai JW, Mao B, Yang WL, Liang S, Lu HW, Xu JF. Asthma-COPD overlap syndrome showed more exacerbations however lower mortality than COPD. QJM. 2017;110(7):431-436.

11. Diaz-Guzman E, Khosravi M, Mannino DM. Asthma, chronic obstructive pulmonary disease, and mortality in the U.S. population. COPD. 2011;8(6):400-407.

12. Hospers JJ, Postma DS, Rijcken B, Weiss ST, Schouten JP. Histamine airway hyper-responsiveness and mortality from chronic obstructive pulmonary disease: a cohort study. Lancet. 2000;356(9238):1313-1317.

13. Suzuki M, Makita H, Konno S, et al; Hokkaido COPD Cohort Study Investigators. Asthma-like features and clinical course of chronic obstructive pulmonary disease: an analysis from the Hokkaido COPD cohort study. Am J Respir Crit Care Med. 2016;194(11):1358-1365.

14. Cosio BG, Soriano JB, López-Campos JL, et al; CHAIN Study. Defining the asthma-COPD overlap syndrome in a COPD cohort. Chest. 2016;149(1):45-52.

15. Yamauchi Y, Yasunaga H, Matsui H, et al. Comparison of in-hospital mortality in patients with COPD, asthma and asthma-COPD overlap exacerbations. Respirology. 2015;20(6):940-946.

16. Louie S, Zeki AA, Schivo M, et al. The asthma-chronic obstructive pulmonary disease overlap syndrome: pharmacotherapeutic considerations. Expert Rev Clin Pharmacol. 2013;6(2):197-219.
17. Soriano JB, Davis KJ, Coleman B, Visick G, Mannino D, Pride NB. The proportional Venn diagram of obstructive lung disease: two approximations from the United States and the United Kingdom. Chest. 2003; 124(2):474-481.

18. Calle Rubio M, Casamor R, Miravitlles M. Identification and distribution of COPD phenotypes in clinical practice according to Spanish COPD Guidelines: the FENEPOC study. Int J Chron Obstruct Pulmon Dis. 2017;12:2373-2383.

19. Koblizek V, Milenkovic B, Barczyk A, et al. Phenotypes of COPD patients with a smoking history in Central and Eastern Europe: the POPE Study. Eur Respir J. 2017;49(5):1601446.

20. Miravitlles M, Barrecheguren M, Roman-Rodríguez M. Frequency and characteristics of different clinical phenotypes of chronic obstructive pulmonary disease. Int J Tuberc Lung Dis. 2015;19(8): 992-998.

21. Cosio BG, Soriano JB, López-Campos JL, et al. Distribution and outcomes of a phenotype-based approach to guide COPD management: results from the CHAIN cohort. PLoS One. 2016;11(9):e0160770.

22. Marín JM, Ciudad M, Moya V, et al. Airflow reversibility and long-term outcomes in patients with COPD without comorbidities. Respir Med. 2014;108(8):1180-1188.

23. Arkhipov V, Arkhipova D, Miravitlles M, Lazarev A, Stukalina E. Characteristics of COPD patients according to GOLD classification and clinical phenotypes in the Russian Federation: the SUPPORT trial. Int J Chron Obstruct Pulmon Dis. 2017;12:3255-3262.

24. Soler-Cataluña JJ, Martínez-García MA, Román Sánchez P, Salcedo E, Navarro M, Ochando R. Severe acute exacerbations and mortality in patients with chronic obstructive pulmonary disease. Thorax. 2005;60(11): 925-931.

25. Soler-Cataluña JJ, Martínez-García MA, Sánchez LS, Tordera MP, Sánchez PR. Severe exacerbations and BODE index: two independent risk factors for death in male COPD patients. Respir Med. 2009; 103(5):692-699.

26. Suissa S, Dell'Aniello S, Ernst P. Long-term natural history of chronic obstructive pulmonary disease: severe exacerbations and mortality. Thorax. 2012;67(11):957-963.

27. Clinical practice guideline for the diagnosis and treatment of patients with chronic obstructive pulmonary disease (COPD) - the Spanish COPD Guideline (GesEPOC). 2017 version. Arch Bronconeumol. 2017; 53 (Suppl 1):2-64.

28. Garcia IS, Clarà PC. Causes of death and prediction of mortality in COPD. Arch Bronconeumol. 2010;46:343-346.

29. Domingo-Salvany A, Lamarca R, Ferrer M, et al. Health-related quality of life and mortality in male patients with chronic obstructive pulmonary disease. Am J Respir Crit Care Med. 2002;166(5):680-685.

30. Solanes I, Casan P, Sangenis M, Calaf N, Giraldo B, Guell R. Factores de riesgo de mortalidad en la EPOC. [Risk factors for mortality in COPD]. Arch Bronconeumol. 2007;43(8):445-449. Spanish.

31. Martinez FJ, Foster G, Curtis JL, et al; NETT Research Group. Predictors of mortality in patients with emphysema and severe airflow obstruction. Am J Respir Crit Care Med. 2006;173(12): 1326-1334.

32. Ries AL, Kaplan RM, Limberg TM, Prewitt LM. Effects of pulmonary rehabilitation on physiologic and psychosocial outcomes in patients with chronic obstructive pulmonary disease. Ann Intern Med. 1995;122(11):823-832.

33. Moreno A, Montón C, Belmonte Y, Gallego M, Pomares X, Real J. Causas de muerte en pacientes con EPOC grave. Factores pronósticos. [Causes of death and risk factors for mortality in patients with severe COPD]. Arch Bronconeumol. 2009;45(4):181-186. Spanish.

34. Zielinski J, MacNee W, Wedzicha J, et al. Causes of death in patients with COPD and chronic respiratory failure. Monaldi Arch Chest Dis. 1997;52(1):43-47.

35. De Abajo Larriba AB, Méndez Rodríguez E, González-Gallego J, et al. Estimating the prevalence of phenotypes in patients with pulmonary obstructive disease. ADEPOCLE study. Nutr Hosp. 2017;34(1): 180-185. 
International Journal of COPD

\section{Publish your work in this journal}

The International Journal of COPD is an international, peer-reviewed journal of therapeutics and pharmacology focusing on concise rapid reporting of clinical studies and reviews in COPD. Special focus is given to the pathophysiological processes underlying the disease, intervention programs, patient focused education, and self management protocols.

\section{Dovepress}

This journal is indexed on PubMed Central, MedLine and CAS. The manuscript management system is completely online and includes a very quick and fair peer-review system, which is all easy to use. Visit $\mathrm{http}: / / \mathrm{www}$.dovepress.com/testimonials.php to read real quotes from published authors.

Submit your manuscript here: http://www.dovepress.com/international-journal-of-chronic-obstructive-pulmonary-disease-journal 